\title{
A study to assess predictive value of yolk sac diameter by transvaginal sonography with the pregnancy outcome
}

\author{
Saniya Sheikh ${ }^{1}$, Anjana B. ${ }^{2 *}$
}

\begin{abstract}
${ }^{1}$ Department of Obstetrics and Gynecology, SDM Medical College and Hospital, Dharwad, Karnataka, India
${ }^{2}$ Obstetrician, District Hospital Thoubal, Government of Manipur, Khangabok, Manipur, India
\end{abstract}

Received: 02 January 2020

Accepted: 29 January 2020

\author{
*Correspondence: \\ Dr. Anjana B., \\ E-mail: statisticclinic2018@gmail.com
}

Copyright: () the author(s), publisher and licensee Medip Academy. This is an open-access article distributed under the terms of the Creative Commons Attribution Non-Commercial License, which permits unrestricted non-commercial use, distribution, and reproduction in any medium, provided the original work is properly cited.

\begin{abstract}
Background: Ultrasonography is one of the most important and useful diagnostic tools in the field of modern medicine. Being non-invasive, safe and without hazards of radiation, it has gained wide acceptability, as an integral part of basic investigative procedures. A yolk sac can be detected easily by transvaginal sonography when the mean gestational sac diameter is 5 to $6 \mathrm{~mm}$. Generally, the yolk sac should be observed when a gestational sac measures greater than 8 . The yolk sac is situated between the amnion and the chorion.

Methods: The present Prospective study was conducted in the department of obstetrics and gynecology, K. L. E. S. Dr. Prabhakar Kore charitable Hospital and Medical Research Centre, Belagavi during the period of January 2015 to February 2016. Records of pregnant women registering between 6 to 10-week 6 days' period of gestation in OPD at KLES Dr. Prabhakar Kore Charitable Hospital and Medical Research Centre, Belagavi and who were fulfilling eligible selection criteria were studied prospectively.

Results: A total of 254 study participants were included in the study and analysed. In this study, 49 cases were from age group of 20 years or less than 20 years i.e. around $19.29 \%$ of total study population. Majority of the cases were with normal yolk sac diameter (YSD) i.e. around 201 cases which accounts for $79.13 \%$ of total study population and total number of cases with abnormal yolk sac diameter (YSD) were 53 which accounts for $20.87 \%$ of total study population.

Conclusions: Measurement of the secondary yolk sac diameter between $6^{\text {th }}$ to $10^{\text {th }}$ weeks 6 days of gestation can be used as a valuable tool in predicting outcome of the pregnancy.
\end{abstract}

Keywords: Outcome, Pregnancy, Transvaginal, Ultrasonography, Yolk sac

\section{INTRODUCTION}

Ultrasonography is one of the most important and useful diagnostic tools in the field of modern medicine. Being non-invasive, safe and without hazards of radiation, it has gained wide acceptability, as an integral part of basic investigative procedures. The convenience, high portability, rapidity, and accuracy are few of the advantages of ultrasound over the other procedures. In the last two decades, ultrasound has become an essential diagnostic imaging modality in the field of obstetrics and is being extensively used for evaluation of pregnancy. Obstetrical ultrasound enables the clinician to evaluate the development, growth, and well-being of the fetus. The ability to study the fetus in the intrauterine environment has been notably enhanced by dramatic improvement in imaging. Although static scan imaging may compliment ultrasound studies, obstetrical examination should always be accompanied by real time modalities. ${ }^{1}$ Transvaginal approach is commonly used in the first trimester. In the standard transabdominal ultrasonography lower frequencies with poorer axial 
resolution (ability to distinguish two separate points in the direct line of the ultrasound beam) are being used to image structures deeper in the body such as pelvic organs. The recent development of higher frequency (5 and $7.5 \mathrm{MHz}$ ) transvaginal transducer probe has resulted in the increased resolution of the female pelvic organs as the endovaginally probe is placed close to the pelvic organs than the transabdominal probe. With transabdominal scanning, the gestational sac is reliably seen in the uterus by 6 weeks, and fetal echoes and cardiac activity by 7 weeks. With transvaginal scanning these are seen about one week earlier. Transabdominal scanning is used predominantly in second and third trimesters of gestation. Its use in first trimester is relatively limited and mostly diagnostic in nature. The introduction of the higher frequency transvaginal probe, with its higher resolution of images, opens new possibilities to study early gestation. ${ }^{2}$

A yolk sac can be detected easily by transvaginal sonography when the mean gestational sac diameter is 5 to $6 \mathrm{~mm}$. Generally, the yolk sac should be observed when a gestational sac measures greater than 8 . The yolk $\mathrm{sac}$ is situated between the amnion and the chorion. The amnion is thin and difficult to visualize and best seen when perpendicular to the ultrasound beam. The amnion grows rapidly during pregnancy and fuses with the chorion between 12 and 16 weeks of gestation. ${ }^{1,3}$

Most important benefit of sonographic evaluation of yolk sac at present is confirmation of intrauterine pregnancy. Yolk sac can be detected with TVS in chorionic cavity from $5^{\text {th }}$ to $12^{\text {th }}$ week of menstrual age. In normal pregnancy it is identified by YSD of 3 to $5 \mathrm{~mm}$ by TVS. ${ }^{4}$ It has been studied that sonographic features of yolk sac like shape, size and internal structure of yolk sac can be associated with gestational outcome. So, any gross changes in shape and size could indicate dysfunction of maternofoetal transport system and may be an indicator of impending embryonic demise.

Objective of this study was to assess predictive value of yolk sac diameter by transvaginal sonography with the pregnancy outcome.

\section{METHODS}

The present prospective study was conducted in the department of obstetrics and gynecology, K. L. E. S. Dr. Prabhakar Kore charitable Hospital and Medical Research Centre, Belagavi during the period of January 2015 to February 2016.

Records of pregnant women registering between 6 to 10week 6 days' period of gestation in OPD at KLES Dr. Prabhakar Kore Charitable Hospital and Medical Research Centre, Belagavi and who were fulfilling eligible selection criteria were studied prospectively. A total of 254 pregnant Mother who fulfilled the inclusion criteria during the study period were included in the study.

\section{Inclusion criteria}

- Pregnant women registering at K. L. E. S. Dr. Prabhakar Kore Charitable Hospital and MRC, Belagavi

- Gestational age between 6-10 weeks 6 days.

\section{Exclusion criteria}

- Molar pregnancy

- Ectopic pregnancy

- Women with congenital anomalies of uterus and cervix

- Multiple gestation

- Women with known endocrine disorder causing abnormal pregnancy outcome e.g. hypothyroidism, diabetes mellitus.

The findings were noted from the ultrasound records of the women who were evaluated for yolk sac diameter by transvaginal sonography between 6 to 10 week 6 days of period of gestation and who were fulfilling eligible selection criteria. Data regarding age, obstetric history and period of gestation of these cases were also noted from the OPD records.

\section{Method of collection of data}

The data was collected from the ultrasound records of the women who were evaluated for yolk sac diameter by transvaginal sonography between 6 to 10 week 6 days of period of gestation and who were fulfilling eligible selection criteria.

Ultrasound was performed by selected trained obstetric sonologists. A $9 \mathrm{~Hz}$ transducer of Phillips HD 11 Ultrasound scan machine was used to perform the scan. Head of the probe was cleaned and covered with a sterile condom. Tip of the condom was smeared with ultrasonic jelly for smooth insertion into the vagina.

The sonography was done with the empty bladder. With the patient in the dorsal position, the probe was inserted slowly into the vagina; so as to obtain a sagittal section of the uterus. The probe was rotated from 12 o 'clock to 9 o 'clock position (anticlockwise) to obtain a transverse section of the uterus.

The yolk sac was identified, and its diameter was measured by placing electronic callipers at inner margins. The range of normal yolk sac diameter was considered to be 3-5 mm. While the yolk sac diameter of $>5 \mathrm{~mm}$ and $<3 \mathrm{~mm}$ was considered as abnormal. Thus, two groups were made with normal and abnormal yolk sac diameter.

The cases falling in these two groups were followed up to 24 weeks. of gestation and considered as normal 
pregnancy outcome if pregnancy continues beyond 24 wks. with no foetal anomaly and abnormal outcome if they have spontaneous abortion, missed abortion, threatened abortion, incomplete abortion, complete abortion, demonstrable foetal anomalies or spontaneous preterm birth.

\section{Statistical analysis}

The data was collected and entered in MS Excel and analysed using SPSS v 21. The continues data was represented with mean and standard deviation. The data was presented in the form of percentages and proportions.

\section{RESULTS}

A total of 254 study participants were included in the study and analysed. In this study, 49 cases were from age group of 20 years or less than 20 years i.e. around $19.29 \%$ of total study population. Majority of cases i.e. around 184 cases belong to 21 to 30 years' age group which accounts for $72.44 \%$ of total study population and
21 cases i.e. $8.27 \%$ of total study population were from 31 years or more than 31 years' age group. The mean age of the study group was $23.94 \pm 3$ years.

Table 1: Distribution of yolk sac diameter in study population.

\begin{tabular}{|lll|}
\hline Yolk sac diameter & Frequency & Percentage \\
\hline Normal & 201 & 79.13 \\
\hline Abnormal & 53 & 20.87 \\
\hline Total & $\mathbf{2 5 4}$ & $\mathbf{1 0 0}$ \\
\hline
\end{tabular}

Majority of the cases were with normal yolk sac diameter (YSD) i.e. around 201 cases which accounts for $79.13 \%$ of total study population and total number of cases with abnormal yolk sac diameter (YSD) were 53 which accounts for $20.87 \%$ of total study population (Table 1 ).

Among the 254 study participants, 220 (86.6\%) of them had a normal outcome of pregnancy and $34(15.4 \%)$ had abnormal outcome of pregnancy.

Table 2: Comparison of yolk sac diameter with outcome of the pregnancy.

\begin{tabular}{|c|c|c|c|c|c|}
\hline \multirow{2}{*}{ Gestational weeks } & \multicolumn{2}{|c|}{ Normal outcome } & \multicolumn{2}{|c|}{ Abnormal Outcome } & \multirow{2}{*}{$p$ value ' $t$ ' test } \\
\hline & Mean & SD & Mean & SD & \\
\hline 6- 7 weeks & 3.28 & 1.01 & 2.9 & 0.12 & 0.412 \\
\hline 7-8 weeks & 3.69 & 0.78 & 3.73 & 1.10 & 0.934 \\
\hline 8-9 weeks & 4.02 & 0.70 & 4.65 & 1.64 & 0.1001 \\
\hline 9-10 weeks & 4.25 & 0.68 & 4.95 & 0.91 & 0.0036 \\
\hline 10-11 weeks & 5.02 & 0.75 & 5.67 & 0.75 & 0.0178 \\
\hline \multirow[t]{2}{*}{ Total } & 4.27 & 0.95 & 4.68 & 1.31 & 0.0261 \\
\hline & \multicolumn{2}{|c|}{$\mathrm{F}=31.33 \mathrm{p}=0.00001$} & $\mathrm{~F}=7.0$ & 00004 & \\
\hline
\end{tabular}

Table 3: Association between outcome in patients with normal and abnormal yolk sac diameter.

\begin{tabular}{|lllll|}
\hline \multirow{2}{*}{ YSD } & Normal outcome & \multicolumn{3}{c|}{ Abnormal Outcome } \\
\cline { 2 - 4 } & Frequency & $\mathbf{\%}$ & Frequency & \% \\
\hline Normal & 184 & 83.6 & 17 & 50 \\
\hline Abnormal & 36 & 16.3 & 17 & 50 \\
\hline Total & $\mathbf{2 2 0}$ & $\mathbf{1 0 0}$ & $\mathbf{3 4}$ & $\mathbf{1 0 0}$ \\
\hline
\end{tabular}

Chi square $=20.17 \mathrm{p}=0.0001$.

The mean diameter of yolk sac in normal outcome of pregnancy with gestational age group of 6 to 7 weeks was $3.28 \mathrm{~mm}$ and for the subsequent gestational age groups, the mean diameter was $3.69 \mathrm{~mm}, 4.02 \mathrm{~mm}, 4.25 \mathrm{~mm}$ and $5.02 \mathrm{~mm}$ respectively at completion of $7,8,9,10$ weeks of gestation respectively. The association of the yolk sac diameter with gestational age was found to be statistically significant.

The mean diameter of yolk sac in abnormal outcome of pregnancy with gestational age group of 6 to 7 weeks was $2.9 \mathrm{~mm}$ and for the subsequent gestational age groups, the mean diameter was $3.73 \mathrm{~mm}, 4.65 \mathrm{~mm}, 4.95 \mathrm{~mm}$ and
$5.67 \mathrm{~mm}$ respectively at completion of $7,8,9,10$ weeks of gestation respectively. The association of the yolk sac diameter with gestational age was found to be statistically significant.

The mean diameters of both normal and abnormal outcomes are compared in each particular gestational age group. The $\mathrm{p}$ value is significant only for two groups i.e. 9 weeks - 9 weeks 6 days and 10 weeks - 10 weeks 6 days group which shows that YSD has significant association with the pregnancy outcome during this particular gestational age (Table 2). 
In this study, total number of cases with normal outcome were 220. Out of which, 184 cases were having normal YSD i.e. $83.64 \%$ of total normal outcome cases. While 36 cases were with abnormal YSD i.e. $16.36 \%$ of total normal outcome cases. Total cases with abnormal outcome were 34; out of which 17 cases belong to each normal and abnormal YSD groups. Here, $p$ value is 0.0001 which is significant; suggestive of YSD has significant effect on pregnancy outcome (Table 3 ).

The sensitivity was more i.e. $66.67 \%$ for 8 weeks -8 weeks 6 days group and 10 weeks - 10 weeks 6 days group. The sensitivity and PPV was not good for 7 weeks - 7 weeks 6 days group. The specificity was high in 9 weeks - 9 weeks 6 days group which was 95.08\%. Among all gestational age groups, the sensitivity, specificity, PPV and NPV was high for 8 weeks - 8 weeks 6 days group which shows that YSD is more valuable tool in predicting pregnancy outcome in this particular gestational age group. In overall, YSD has good NPV i.e. $91.54 \%$ but poor PPV. The overall sensitivity and specificity of YSD was $50 \%$ and $83.64 \%$ in this study (Table 4).

Table 4: Yolk sac as a predictor of pregnancy outcome.

\begin{tabular}{|llll|l|}
\hline Gestational weeks & Sensitivity & Specificity & PPV & NPV \\
\hline 6- 7 weeks & 60 & 78.26 & 37.5 & 90 \\
\hline 7-8 weeks & 0 & 93.1 & 0 & 90 \\
\hline 8-9 weeks & 66.67 & 95 & 66.67 & 95 \\
\hline 9-10 weeks & 36.36 & 95.08 & 57.14 & 89.23 \\
\hline 10-11 weeks & 66.67 & 64.18 & 20 & 93.48 \\
\hline Total & $\mathbf{5 0}$ & $\mathbf{8 3 . 6 4}$ & $\mathbf{3 2 . 0 8}$ & $\mathbf{9 1 . 5 4}$ \\
\hline
\end{tabular}

This is the graph showing area under the curve; which is here around 0.6682 . It means around $66.82 \%$ of total cases of study population fall under this curve which is nothing but the accuracy of this study.

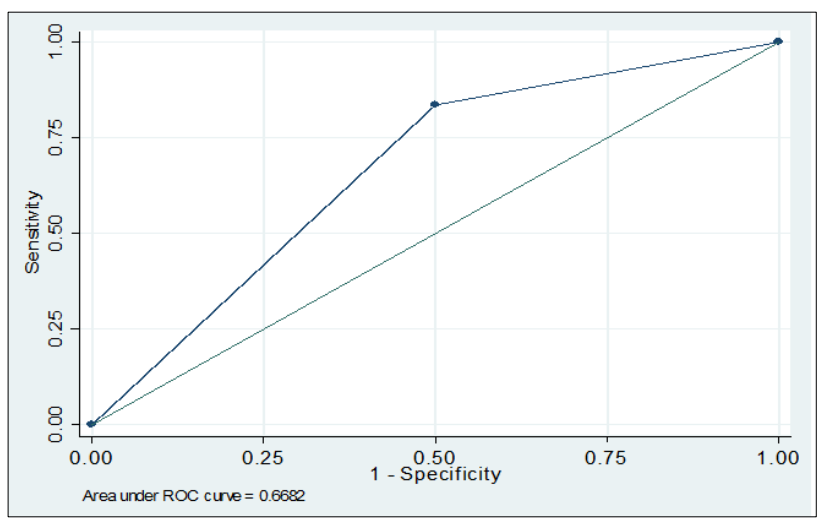

Figure 1: ROC Curve for the predicting the outcome of pregnancy with yolk sac diameter.

\section{DISCUSSION}

The reliability of ultra-sonographic visualization of the human yolk sac is well established. In this study, 254 pregnancies were analyzed between 6 to 10 weeks 6 days' period of gestation to determine the role of yolk sac diameter as a predictor of pregnancy outcome.

In the study by Srivastav et al, in India, the mean YSD was noted as $3.7 \pm 1.8 \mathrm{~mm}$ and the diameter of the smallest yolk sac was $1.25 \mathrm{~mm}$ and that of the largest was 8.96 mm. ${ }^{5}$ In this study, mean YSD was $4.32 \pm 1.01 \mathrm{~mm}$. In the study conducted by Tan $\mathrm{S}$ et al in Turkey, the mean YSD was $3.2 \pm 0.7 \mathrm{~mm}^{4}$ So in present study, the mean YSD was more than these other two studies and the largest YSD was smaller in present study than that of study by Srivastav et al, in India. ${ }^{5}$

In this study, mean YSD was progressively increasing with advancing gestational age from 6 weeks to 10 weeks 6 days. Cepni et al, demonstrated the steady increase in YSD from 5 to 11 weeks of gestation in normal pregnancies after which it disappears by 12 weeks. ${ }^{6}$ Chama et al, reported a linear increment in mean YSD from $2.27 \mathrm{~mm}$ at 5 weeks of gestation to $5.61 \mathrm{~mm}$ at 11 weeks of gestation. ${ }^{7}$ Lindsay et al, reported that yolk sac grows at a rate of approximately $0.1 \mathrm{~mm}$ per $\mathrm{mm}$ growth of the MSD when the MSD is less than $15 \mathrm{~mm}$ and then slows to $0.03 \mathrm{~mm}$ per $\mathrm{mm}$ growth of MSD. ${ }^{8}$

Finding was also comparable to the Indian study by Rajani $\mathrm{N}$ et al in which progressively increased mean YSD was found with advanced gestational age between 5 - 9 weeks of GA, followed by either their disappearance $(73.61 \%)$, or decreased size $(26.38 \%)$ thereafter at 11 weeks of GA in cases with normal outcome. ${ }^{3}$

The mean age in this study was $23.94 \pm 3$. There was no significant association between YSD and maternal age in our study ( $\mathrm{p}$ value $=0.452$ )

In the study by Moradan et al in Iran, the mean age of the study group was $28.1 \pm 5.8$ years and that of the control group was $28 \pm 4.8$ years, which was not statistically significant $(\mathrm{p}=0.876) .{ }^{9}$ Also in the another study by Adiga et al, in India, there were no significant differences between outcomes with regard to maternal age. ${ }^{10}$ 
As depicted, the yolk sac diameter of abnormal outcomes varied widely, both above and below the mean yolk sac diameter for normal outcomes, hence the mean yolk sac diameter of abnormal outcomes may not differ significantly from that of normal outcomes. This is contradictory to the study by Rajani $\mathrm{N}$ et al, in which a highly significant difference was detected between mean YSD of both groups $(\mathrm{p}<0.001) .^{3}$

In the present study, we had $13.38 \%$ incidence $(34 / 254)$ of abnormal pregnancy outcome. This is in concordance with the study by Roth et al, who estimated the frequency of spontaneous abortion to be $15 \%$ of recognizable pregnancies. ${ }^{11}$ In the study conducted by Lindsay et al, to evaluate the role of yolk sac size and shape as predictor of pregnancy outcome, the incidence of abnormal pregnancy outcome was $32.7 \%(159 / 486) .{ }^{12}$ But the criteria for defining an abnormal outcome varies in different studies, for example in our study, abnormal outcome was defined as spontaneous abortion, or missed abortion before 24 weeks of gestation or demonstrable fetal anomalies whereas, Lindsay et al, considered abnormal outcome as first trimester embryonic or fetal death or demonstrable fetal anomaly.

In an Indian study Rajani $\mathrm{N}$ et al, the incidence of abnormal outcome was $20 \%$ which included missed abortion and blighted ova before 12 weeks of gestation. ${ }^{3}$

In this study authors have also estimated the ideal time to perform the transvaginal scan, in order to achieve the highest possible sensitivity, specificity, positive and negative predictive value. Sensitivity, PPV and NPV was highest at $8^{\text {th }}$ week of gestation and specificity was highest at $9^{\text {th }}$ week of gestation. The sensitivity and PPV were very poor at $7^{\text {th }}$ week of gestation. The overall sensitivity, specificity, positive and negative predictive value of predicting pregnancy outcome in this study was $50 \%, 83.64 \%, 32.08 \%$ and $91.54 \%$ respectively.

The sensitivity, specificity and PPV of predicting an abnormal outcome was $26.9 \%, 92.7 \%$ and $51.1 \%$ respectively, reported by Lindsay et al. ${ }^{12}$ The results of our study are comparable to the results of this study. Also, in other study by Kucuk et al, they found a yolk sac diameter out of 2 standard deviations of the mean for the menstrual age allowed prediction of an abnormal pregnancy outcome with a sensitivity of $65 \%$, a specificity of $97 \%$, PPV of $71 \%$ and a NPV of $95 \% .^{13}$

Statistical analysis of yolk sac diameter as a predictor of pregnancy outcome was significant when measured between $8^{\text {th }}$ and $9^{\text {th }}$ week of Gestation. $(\mathrm{p}<0.05)$. When the measurement was taken between $6^{\text {th }}$ to $7^{\text {th }}$ week of gestation and at $10^{\text {th }}$ week of gestation, the results were not significant with a $p$ value of $0.2420,1.000$ and 0.1574 respectively. This is in contrast to the studies done previously in which yolk sac could be accurately evaluated from 5 completed weeks of GA. This might have resulted due to the small yolk sac size at this time of gestation combined with various other confounding factors like inaccuracy of menstrual dating, expertise of the sonographer, resolution of the transducers.

In a more recent study by Berdahl DMJ, Blaine, et al, the authors have examined the value of a specific cut-off (5 $\mathrm{mm})$ to allow easier patient counselling. ${ }^{14}$ They concluded pregnancies with MSD $\geq 5 \mathrm{~mm}$ on early ultrasound require monitoring and counselling about a threefold increased risk for first-trimester loss independent of maternal risk factors such as age, body mass index, polycystic ovary syndrome, smoking, and diabetes. In addition, their study shows for the first time that enlarged yolk sac diameter may be associated with an increased risk of preterm delivery.

In this study, when the association between outcomes in pregnancies with normal and abnormal YSD was studied, the $\mathrm{p}$ value was highly significant $(\mathrm{p}=0.0001)$ which was in accordance with the study by Prabhjot et al, where $p$ value was $<0.001$ and also with the other study by Srivastav et al where $\mathrm{p}$ value was $<0.001$. 5,15

Thus, it shows highly significant correlation between YSD and pregnancy outcome.

\section{CONCLUSION}

Measurement of the secondary yolk sac diameter between $6^{\text {th }}$ to $10^{\text {th }}$ week 6 days of gestation can be used as a valuable tool in predicting outcome of the pregnancy. The yolk sac is the first structure to appear in the gestational sac, which confirms an intra uterine pregnancy. Yolk sac measurement can be used as a tool to evaluate pregnancy outcome, even before the detection of the embryo. This it helps in counselling the parents regarding the risk of miscarriage and the need for follow up ultrasound examinations. It is particularly helpful to counsel patients with history of threatened or recurrent abortion who abort despite resting in the hospital for many weeks. It also helps in pursuing a more active line of management if required.

\section{Funding: No funding sources}

Conflict of interest: None declared

Ethical approval: The study was approved by the Institutional Ethics Committee

\section{REFERENCES}

1. Monteagudo A, Timor-Tritsch IE, Sharma S. Early and simple determination of chorionic and amniotic type in multifetal gestations in the first fourteen weeks by high-frequency transvaginal ultrasonography. Am J Obstet Gynecol. 1994;170:824-9.

2. Acharya G1, Morgan H. First-trimester, threedimensional transvaginal ultrasound volumetry in normal pregnancies and spontaneous miscarriages. Ultrasound Obstet Gynecol. 2002;19(6):575-9. 
3. Nawal R, Khuteta S, Jain D, Khuteta PP, Meena VK. To assess value of yolk sac in predicting pregnancy outcome during first trimester: observational study. Natl J Med Res. 2012;2(3):343-7.

4. Tan S, Pektaş MK, Arslan H. Sonographic evaluation of the yolk sac. J Ultrasound Med. 2012;31:87-95.

5. Srivastava G, Nagwani M, Pasricha N, Tewari V, Siddiqui MS, Sthapak E. Size of yolk sac by ultrasonography and its correlation with pregnancy outcome. Int J Anat Res. 2016;4(1):2052-7.

6. Cepni I, Bese T, Ocal P. Significance of yolk sac measurements with vaginal sonography in the first trimester in the prediction of pregnancy outcome. Acta Obstet Gynecol Scand. 1997;76:969-72.

7. Chama CM, Marupa JY, Obed JY. The value of the secondary yolk sac in predicting pregnancy outcome. J Obstet Gynaecol. 2005;25(3):245-7.

8. Lindsay DJ, Lovett IS, Lyons EA, Levi CS, Zheng $\mathrm{XH}$, Holt SC, et al. Yolk sac diameter and shape at endovaginal US: predictors of pregnancy outcome in the first trimester. Radiol. 1992;183(1):115-8.

9. Moradan S, Forouzeshfar M. Are abnormal yolk sac characteristics important factors in abortion rates? Int J Fertil Steril. 2012;6(2):127-30.

10. Adiga P, Selvi C, Rai L, Hebbar S. Evaluation of yolk sac diameter and embryonic heart rate as prognostic factors of gestational outcome in early singleton pregnancies. Sch J App Med Sci. 2015;3(2A):543-50.

11. Roth TF, Linden CD. IgG receptors on fetal chick yolk sac. J Cell Sci. 1978;33:317-28.

12. Lindsay DJ, Lovett IS, Lyons EA. Yolk sac diameter and shape at endovaginal US: predictors of pregnancy outcome in the first trimester. Radiol. 1992;183:115-8.

13. Kucuk T, Duru NK, Yenen MC, Dede M, Ergün A, Baer I. Yolk sac size and shape as predictors of poor pregnancy outcome. J Perinat Med. 1999;27:316-20.

14. Berdahl DM, Blaine J, Voorhis BV, Dokras A. Detection of enlarged yolk sac on early ultrasound is associated with adverse pregnancy outcomes. Fertil Steril. 2010;94(4):1535-7.

15. Prabhjot M, Nirmala D, Dhvanit T. Evaluation of yolk sac diameter on abdominal scan and its fetal outcome. Int J Obst Gynaecol Res. 2016;3(6):36874.

Cite this article as: Sheikh S, Anjana B. A study to assess predictive value of yolk sac diameter by transvaginal sonography with the pregnancy outcome. Int J Reprod Contracept Obstet Gynecol 2020;9:9971002. 